\title{
A Medical Support in Offshore Racing Workshop, 6 November 2015, Sanya, China
}

\author{
Nebojša Nikolić ${ }^{1}$, llona Denisenko ${ }^{2}$, Roger Nilson ${ }^{3}$, Spike Briggs $^{4}$, Jean Christophe Fimbaultt, \\ Arne Johan Ulven ${ }^{6}$, Margriet Pannevis ${ }^{7}$, Simon Forbes ${ }^{8}$ \\ ${ }^{1}$ Workshop Chairman (ISAF Medical Commission Member), Croatia \\ ${ }^{2}$ President International Maritime Health Association, Russia \\ ${ }^{3} 7$ Whitbread RTWR/Volvo Ocean Races + 2 Multihull Circumnavigations, Sweden \\ ${ }^{4}$ Medical Support Offshore Ltd., Great Britain \\ ${ }^{5}$ Emergency Medic Douarnenez Hospital, France \\ ${ }^{6}$ Bergen Telemedical Support, Norway \\ ${ }^{7}$ Chairman ISAF Medical Commission, Netherlands \\ ${ }^{8}$ ISAF Technical and Offshore Manager, United Kingdom
}
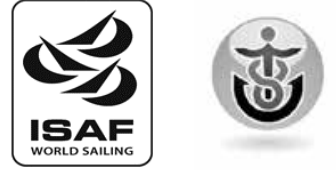

\section{IMHA}

\section{INTRODUCTION}

The safety and health of sailors offshore is of major concern. Mass participation, often with amateur crew, continues to highlight the need for comprehensive integrated support to manage the almost inevitable problems that will occur.

Maritime medicine is a well-established support framework for commercial shipping, underwritten by governmental regulatory authorities. There is obvious overlap and shared areas of concern with the newly-emerging field of sailing sport medicine. Although the on-board environment and population of sailors is somewhat different for sailing, much value in commercial shipping guidelines and practices will benefit sailors undertaking offshore yacht racing.

Medical teams involved in planning and managing offshore yacht racing will benefit from an internationally recognised reference document which addresses all aspects of medical support for such events. A central forum for discussing common medical problems that arise in this arena will facilitate future development of medical support for offshore yacht racing.

\section{THE AIM OF THE WORKSHOP}

The aim of the workshop was:

- to present the context of historical experiences of yacht crew, both enduring and managing illness and trauma during offshore yacht racing;
- to present the conclusions from the IMHA Workshop 'Management of Medical Incidents at Sea' held in London 2-3 February 2015;

- to evaluate the current medical management guidelines developed for the foremost offshore yacht races;

- to identify the basic principles of medical support for such events;

- to evaluate the gathered evidence on medical training for crews in offshore yacht racing;

- to evaluate the gathered evidence on medical kit guidelines and manuals currently used in offshore yacht racing;

- to evaluate the gathered evidence on tele-medical support services currently available to offshore yacht racing.

\footnotetext{
CURRENT POSITION ON MEDICAL SUPPORT FOR SPECIFIC OFFSHORE RACES

Prior to the workshop, a survey was performed to gather information on the details for medical support from the organising authorities for the foremost offshore yacht races. The table summarising the results of this survey is included in Appendix.

In summary, there is a variety of practice in all the yacht races surveyed, in terms of on-board medical kit, prior medical training, whether pre-arranged tele-medical support
} 
is required, and the use of a specific medical manual. In addition, there is a wide spectrum of practice in assessment of medical fitness prior to taking part in a race, and whether a minimum fitness standard is defined.

At present, discrepancies, or lack of concordance, between medical training, medical kits and recommended medical manual may cause suboptimal treatment of sailors suffering from serious illness or injures.

In addition, tele-medical support services operating without knowledge of the on-board environment in offshore races, medical kit carried and training of yacht crew, may not provide best advice on medical interventions that crew can achieve.

\section{RECOMMENDATIONS}

\section{MEDICAL TRAINING}

Medical training has to take into account the type of yacht racing undertaken, the time and distance remote from definitive medical assistance, and the medical kit carried by the yacht. In general, yacht races venturing into more challenging environments require more extensive medical training.

Ideally, medical training should involve theory, practical skills, and simulation of practical scenarios on board the vessel, including at sea.

The Working Group support the Submission SR 23-15 to increase for Category 0 races 6.05.1, the number of crew required from one to two, who shall have a valid STCW A IV / 4-2 (Proficiency in Medical Care) certificate. In addition, the Working Group also supports the amendments increasing medical training for Category 1 and 2 races.

\section{MEDICAL KIT}

A medical kit should contain medicines and medical equipment to enable the treatment of most illnesses and trauma that may occur during offshore yacht racing. This includes the variable period of time that a casualty may require treatment and maintenance on-board before professional medical assistance can be obtained or casualty evacuated. Medicines may include prescription-only medicines and controlled medicines that may be subject to statutory regulation.

The contents of the medical kit should be appropriate in terms of both variety and quantity of medicines and medical equipment, reflecting the number of crew and the category of race being undertaken.

The medical manual carried on board should include details on the safe usage of all medical kit contents, to optimise treatment.

The organisation of the medical kit should allow intuitive usage, possibly utilising a colour-coded modular arrangement, and should include a readily accessible list of contents.

Medications should be listed by generic name, followed by indication for use, and recommended dosage.

The medical training program of the crew should be based upon instruction on what resources are in the medical kit, how it is laid out, and how to use the contents to best effect.

Consideration should be given to including a medical grab bag as part of the medical kit inventory. The contents of the medical grab bag should include items likely to be necessary in the event the crew abandons ship and resorts to the life raft.

The Working Group recommends formulating suggested medical kit content lists for different category races. Such medical kits would be regarded as a minimum standard, and not a substitute if national regulations are more comprehensive.

\section{MEDICAL MANUAL}

The medical manual carried on board the vessel should reflect, and be integrated with, both the content of the medical kit and the also the medical training of the crew.

The medical manual should be appropriate for the category of race, and should also reflect the operating language of the yacht.

The medical manual should guide crew in the recognition of the signs ('red flags') of severe illness or trauma, and the immediate treatment that may be required. Treatment pathways should give guidance to crew as to when referral to telemedical support services is appropriate.

The medical manual should preferably take two forms: a water-resistant hard copy version, and also an electronic searchable version. Either or both should be part of the medical resource on board the yacht.

\section{TELEMEDICINE}

The Working Group recommends for ISAF Category 0 and 1 races (Vendee Globe, Barcelona World Race, Volvo Ocean Race etc.), where yachts have sufficient connectivity capability, transmission of real-time video for the purposes of telemedical support.

The Working Group recommends for ISAF Category 2 races (Fastnet, Sydney Hobart etc.) the requirement for satellite communication equipment (such Iridium, Inmarsat etc.) for the purposes of telemedical support. This recommendation is for instances where races are beyond the range of VHF or mobile telephone coverage.

The Working Group recommends that Race Organisers provide an arrangement for contact with a telemedical support service. Such a telemedical support service should be capable of receiving live video transmission, images, email, 
sat text and voice communication from offshore (as appropriate for the ISAF category of race as described above). The telemedical support service should be fully cognisant of the typical conditions on board a racing yacht, and also the general geographical location of such yachts, with the potential inherent delay in evacuation of a casualty.

The telemedical support service used by yachts should reflect and be integrated with, both the content of the medical kit on board, the medical manual used by the crew, and also the medical training received by the crew.

The telemedical support service should be experienced in interacting and coordinating with Rescue Coordination Centres (such as MRCCs, JRCCs etc.).

The Working Group recommends that all yachts participating in a race have a single point of contact for advice on medical matters. This could be with the Communication Centre of the Race Organisers, or directly with the telemedical support service. Either entity would have the responsibility of relaying medical information to the Race Organisers, RCCs, relatives etc.

\section{FITNESS STANDARDS}

The Working Group notes the existence of ILO/IMO Guidelines on the Medical Examination of Seafarers. How- ever, at this stage the Working Group does not make a recommendation on the standard of medical fitness for participants in any ISAF Category of yacht race, and hence responsibility in this matter remains with the Race Organisers.

\section{FURTHER ACTIONS TO BE TAKEN}

The Working Group proposes organisation of further workshops on specific aspects of this position paper, with the aim of setting minimum reference standards for offshore races. These workshops should establish a robust evidence base for the frequency and severity of illness and trauma offshore. Risk analyses based on this evidence base will feed a review of the present control measures, with the aim of improving outcomes offshore.

The specific areas to be examined in these future workshops are:

- efficacy of medical training and learning outcomes;

- content of the recommended medical kits for differing ISAF Category of races;

- the structure and content of the ideal medical manual for use on board;

- fitness standards for crew participating in ISAF Category 0 and 1 yacht races. 


\begin{tabular}{|c|c|c|c|c|c|c|}
\hline & 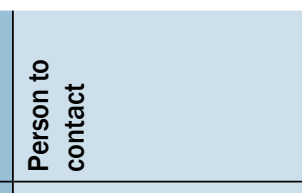 & 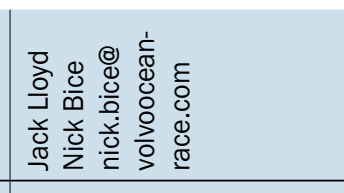 & 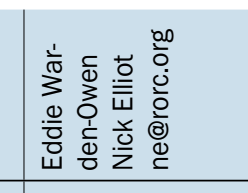 & 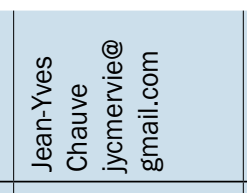 & & 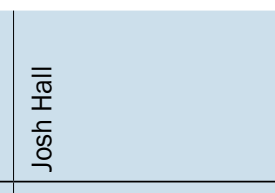 \\
\hline & 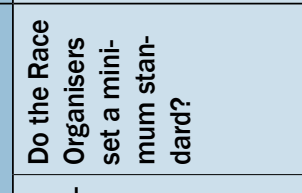 & 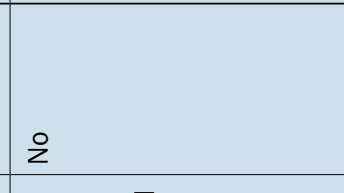 & $\stackrel{2}{2}$ & \& & ₹ & z \\
\hline & 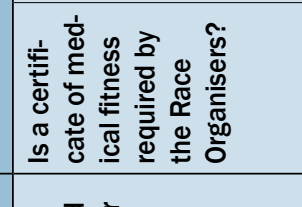 & 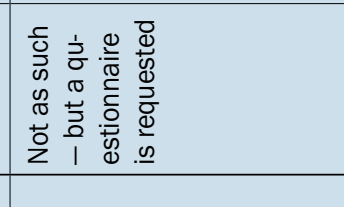 & 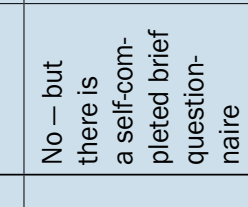 & 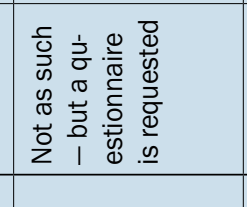 & 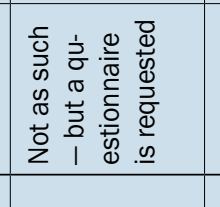 & 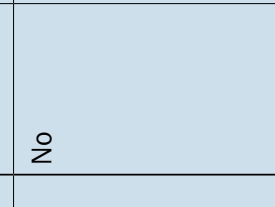 \\
\hline & 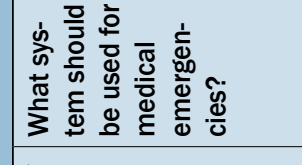 & 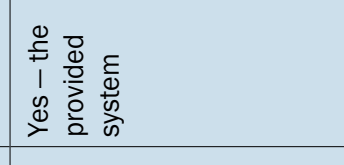 & 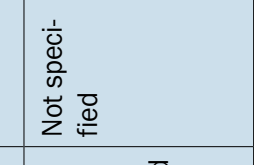 & 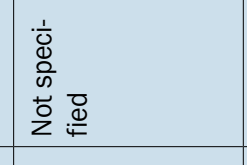 & 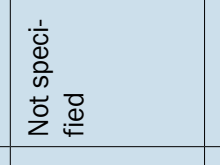 & 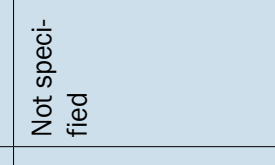 \\
\hline & 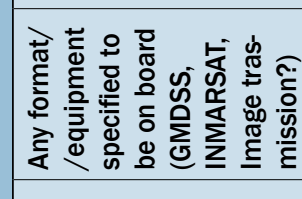 & 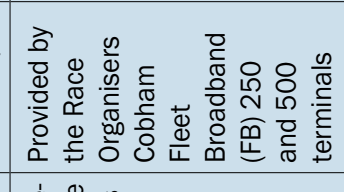 & 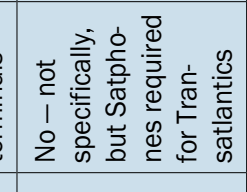 & 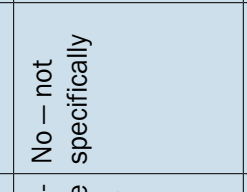 & 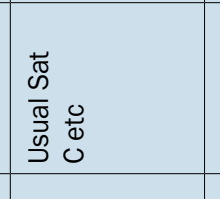 & 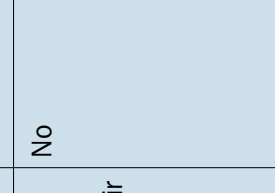 \\
\hline & 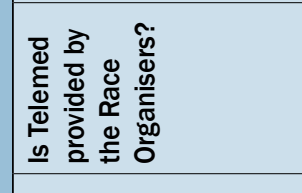 & 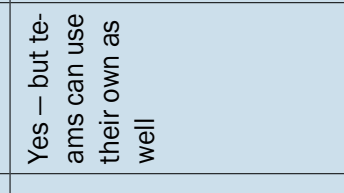 & z & 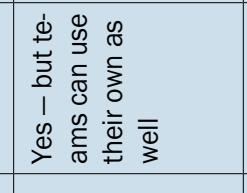 & $\%$ & 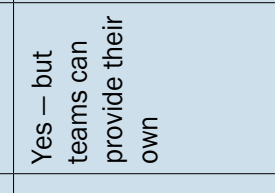 \\
\hline 㐫 & 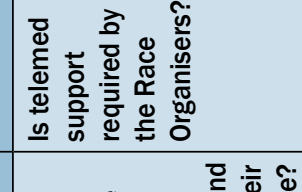 & 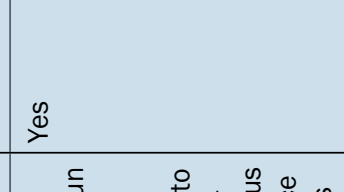 & $\stackrel{2}{z}$ & 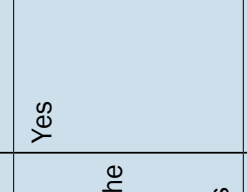 & 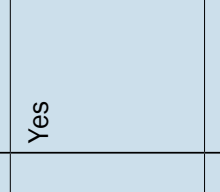 & 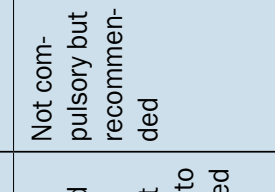 \\
\hline & 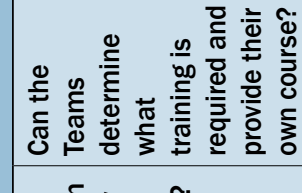 & 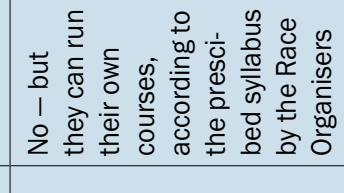 & 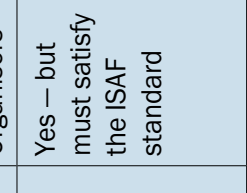 & 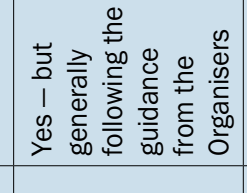 & $\%$ & 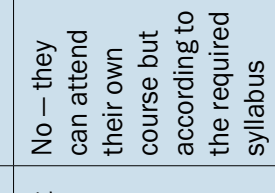 \\
\hline 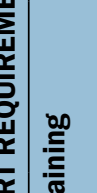 & 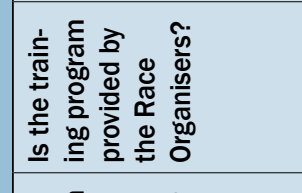 & $\ddot{q}$ & z & z & $\stackrel{2}{z}$ & 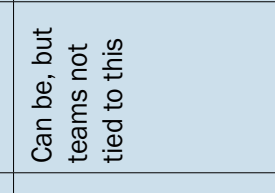 \\
\hline$\sum$ & 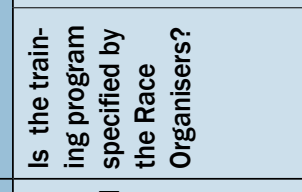 & $\mathscr{0}$ & 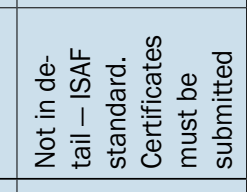 & 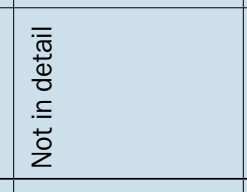 & 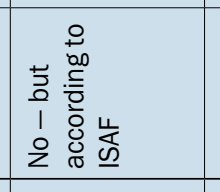 & 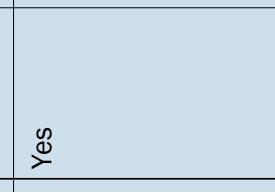 \\
\hline 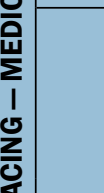 & 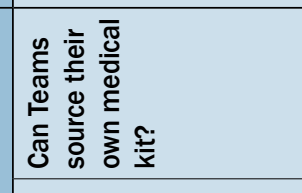 & \& & 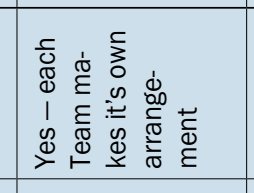 & 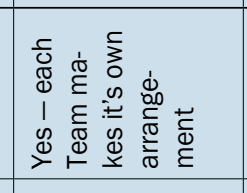 & 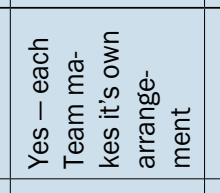 & 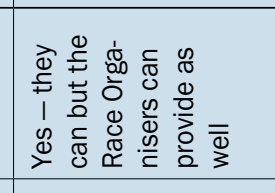 \\
\hline & 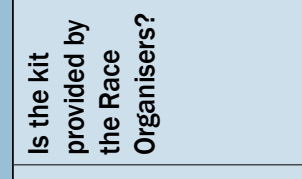 & $g$ & $\stackrel{2}{2}$ & ஜ & \& & 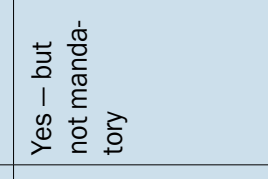 \\
\hline 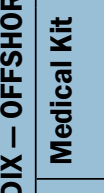 & 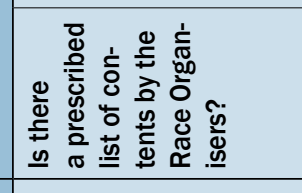 & 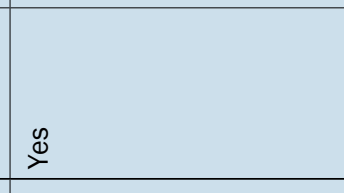 & 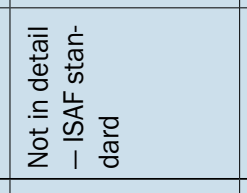 & $\stackrel{g}{x}$ & 总要 & $\stackrel{\mathscr{g}}{\check{q}}$ \\
\hline 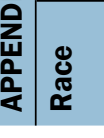 & & 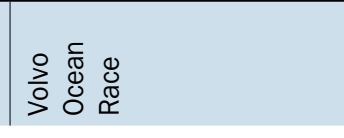 & 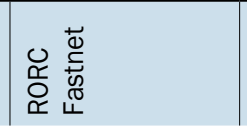 & 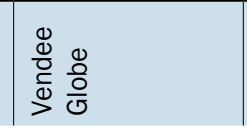 & 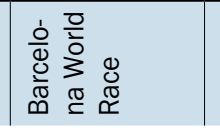 & 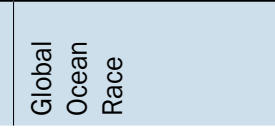 \\
\hline
\end{tabular}




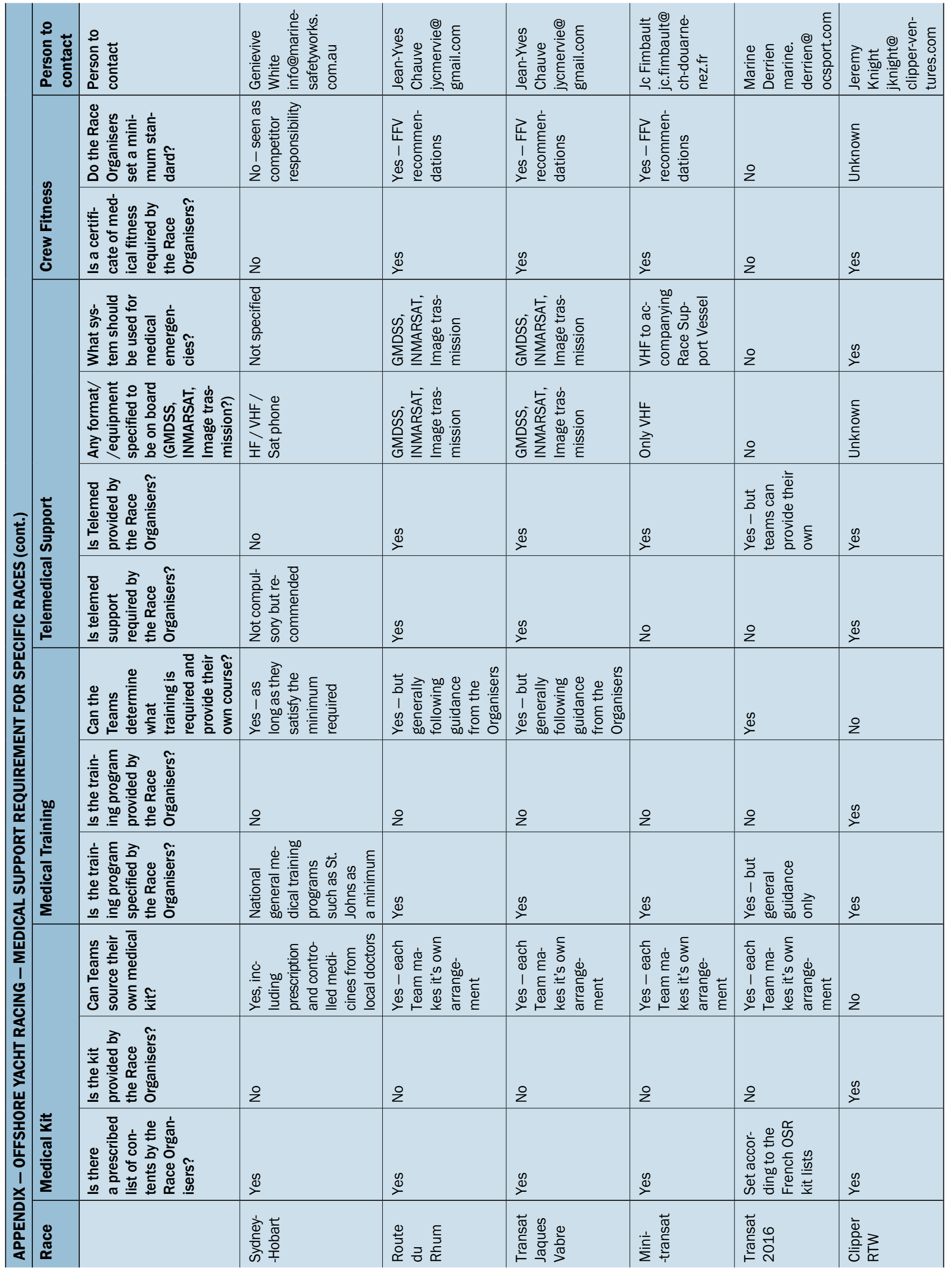

